\title{
COMMENT
}

\section{Are you listening to our children: empowering youth advocates}

\author{
Shale L. Wong ${ }^{1}$ and Jean L. Raphael ${ }^{2}$ \\ Pediatric Research (2020) 87:432-433; https://doi.org/10.1038/s41390-019-0743-7
}

Pediatricians have a unique and privileged relationship with youth and children. We speak with them, to them, and hear concerns from their unique perspectives. Perhaps that is why it is no surprise that we expect them to be part of the dialogue. We understand that it is impossible to know whether we are meeting their needs unless we ask them directly. With parents, family, and teachers, we are positioned to listen and respond to youth needs, guiding where we can toward a healthy and productive future.

In recent times, we are seeing our youth step up and into conversations in prominent and influential ways, attracting different audiences and working to bring others together with unprecedented and unexpected success. Youth leaders are recognizing that policy makers are making choices that will impact their livelihood and their future. Youth are taking on policy, from their own schools and neighborhoods to global forums including the United Nations.

At 16 years of age, Greta Thunberg has captured a worldwide spotlight engaging international leaders with an address to the United Nations General Assembly, as well as testimony for the United States Congress. She articulates the urgency of global climate change consistently pointing to the science and scientists who should be informing policy decisions rather than lobbying for or against specific policies. Ms. Thunberg's reach goes well beyond policy makers themselves, appearing on news and televised outlets, and speaking for gatherings of tens of thousands in public forums. Her social media presence rapidly circled the globe introducing her to millions of individuals and motivating youth activism on the climate crisis around the world. Of further intrigue to pediatric scientists, she is unabashed in recognizing her Asperger's diagnosis as a "superpower" that allows her to speak directly and with precision. Her combination of powers led to being awarded the Amnesty International's Ambassador of Conscience Award and TIME magazine's youngest ever Person of the Year in 2019. As a catalyst mobilizing public advocacy, it remains to be seen how policy leaders and decision makers will choose to listen and respond.

Consider the Parkland survivors who led the \#NeverAgain movement and inspired the March For Our Lives that convened 1.2 million people around the world. This demonstrates another vivid example where youth have mastered social networking and social media to be heard and seen. They have organized into a bold non-profit organization with an evidenceinformed plan for policies that address the public health epidemic of gun violence. The courage embodied by these young people to take on an opposition who literally bears arms is both admirable and provocative. In Florida, where communities felt the repercussions of the tragic shooting at Marjory
Stoneman Douglas High School, they have also been effective. State laws were strengthened in the immediate aftermath. These include raising the age to purchase a firearm to 21 years, required 3-day waiting period for purchasing a gun, and bump stock ban that prevents devices that modify firearms for capability to be used as automatic weapons. The Florida legislature continues to debate at least a half dozen proposals for additional gun legislation this year. At the federal level, momentum fueled by the youth voice influenced the progress of appropriating 25 million in funding for public health firearm research.

The social policy issues that children and youth are taking on are widespread and focus on actions at the community and local level in addition to globally, from climate change, gun violence, and school safety, to immigration and Deferred Action for Childhood Arrivals (DACA), from gender awareness and inclusion, to education rights for women and girls. All are exceptionally complex and require multiple perspectives in order to develop informed policies. In each of these cases there are youth champions who have changed the dialog bringing their voice to the forefront. As clinicians, researchers, and advocates ourselves, how can we support and elevate the youth voice?

Within the clinical realm, we can ask youth directly about what issues are important to them. Every adolescent primary care visit includes a "HEADSS" assessment. In learning about the context of a teen's life, including a question about what they value, not just their behaviors and environments, could reveal opportunities to take initiative and offer a space where they can explore their own priorities. As experts in child development, addressing topics in a meaningful way and opening up discussion would meet them where they are and help to encourage adolescents to share their view of the world.

Pediatric researchers are frequently seeking opportunities to apply the findings of their work and to influence action or behavior change at a local, state, or regional level. Engaging youth to share relevant stories and experiences that illustrate a condition or outcome of the research with other leaders, and to use evidence to inform their efforts offer a partnership that brings power, authenticity, and relevance to data. Cultivating collaborative relationships could be a win-win partnership. Imagine a new advocacy approach to the vaping epidemic with the youth voice speaking out about concerns of the prevalence and risks to their friends. Who better to influence other teens and impart peer pressure to deglamorize vaping than teens themselves? They need expertize from cutting edge research in our field to empower their message.

You know of Malala Yousafzai, the youngest Nobel Peace prize awardee in history, but do you know the youth in your own

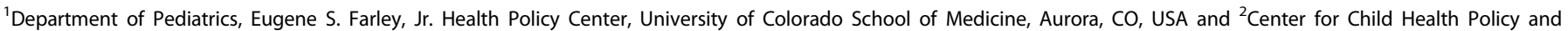
Advocacy, Baylor College of Medicine, Houston, TX, USA

Correspondence: Shale L. Wong (Shale.wong@CUAnschutz.edu)

Received: 27 November 2019 Accepted: 9 December 2019

Published online: 2 January 2020 
Are you listening to our children: empowering youth advocates SL Wong and JL Raphael

community and your own clinic? Are you bringing youth into your research conversations and clinical community discussions? Given the position we are in to know the strengths of our youth, we should support and elevate the youth voice. Pave roads for inviting youth into the conversation. It is our unique opportunity to advocate with them not just for them. Youth connect to each other in ways that we cannot. As pediatricians and child health professionals we have profound respect for children and youth that grows with our daily interactions. When we listen, they will lead.

\section{ACKNOWLEDGEMENTS}

This commentary is submitted on behalf of the Pediatric Policy Council. Both authors meet the requirements for authorship having contributed to concept, revision, and final approval.

\section{ADDITIONAL INFORMATION}

Competing interests The authors declare no competing interests.

Publisher's note Springer Nature remains neutral with regard to jurisdictional claims in published maps and institutional affiliations. 